\title{
National dental policies and socio- demographic factors affecting changes in the incidence of periodontal treatments in Korean: A nationwide population-based retrospective cohort study from 2002-2013
}

\author{
Jae-Hong Lee ${ }^{1}$, Jung-Seok Lee ${ }^{2}$, Jung-Kyu Choi ${ }^{3}$, Hye-In Kweon ${ }^{4}$, Young-Taek Kim ${ }^{4 * \dagger}$ and Seong-Ho Choi ${ }^{2^{*}+}$
}

\begin{abstract}
Background: Dental insurance coverage has recently expanded in Korea. The number of patients diagnosed with periodontal disease (PD), and the actual number of periodontally compromised patients has increased. However, few studies have investigated the relationships between the prevalence of periodontal disease and the incidence of PD treatment, dental insurance policies, and socio-demographic factors. To determine the incidence of periodontal treatments required, the comprehensive longitudinal data of the National Health Insurance Service were used. This study evaluated changes in the incidence of periodontal treatments, using data from the Korean National Health Insurance Cohort Database.

Methods: A random stratified sample of 1,025,340 Korean patients was selected from National Health Insurance database, using 1,476 multistage samplings (of sex, age, and income level) for 12 years from 2002 to 2013. Chi-square analysis, and univariate, and multivariate logistic regression were used to evaluate the association of socio-demographic factors with the prevalence of PD and the incidence of periodontal treatment.

Results: The incidence of periodontal treatment steadily and significantly increased, in both male and female participants, from 2002 to 2013. The increase was associated with socio-demographic factors and changes in national dental insurance policies. The incidence of periodontal treatment evaluated by age is influenced by the changes in national dental policies. These results suggest that the increase in patients diagnosed with PD reflects changes in dental policies and insurance benefits.

Conclusions: This study confirms that national dental policies and socio-demographic factors are related to the incidence of periodontal treatments. The incidence of periodontal treatment is significantly related to the expansion of insurance coverage in South Korea.
\end{abstract}

Keywords: Cohort analysis, Dental insurance, Health insurance, Health services accessibility, Periodontal disease

\footnotetext{
*Correspondence: youngtaek77@naver.com; shchoi726@yuhs.ac

${ }^{\dagger}$ Equal contributors

${ }^{4}$ Department of Periodontology, Ilsan Hospital, National Health Insurance

Service, 100 Ilsan-ro Ilsan-donggu, Goyang 10444, South Korea

2Department of Periodontology, Research Institute for Periodontal

Regeneration, Yonsei University College of Dentistry, 50 Yonsei-ro,

Seodaemun-gu, Seoul 03722, South Korea

Full list of author information is available at the end of the article
} 


\section{Background}

The demands for medical care in modern societies are increasing. These demands result from increases in the aging population, household income, and education levels, and changes in health policies and the medical care systems [1]. Recently, the importance of oralhealth-related quality of life has been recognized $[2,3]$. Periodontal disease (PD) is a disease of the oral cavity, and a major cause of tooth loss in adults [4]. More than half of all adults are affected by some degree of PD, and $11 \%$ of adults suffer from severe and advanced periodontitis [5]. In 2014, in South Korea, 12.9 million people ( $26 \%$ of the current population) received treatment for PD. Periodontal disease is a highly prevalent disease, and is the second most common outpatient disease, after acute bronchitis [6].

Recent expansion of insurance coverage for dental treatment has resulted in an increase in the number of patients diagnosed with PD, and an increase in the identification of periodontally compromised patients [6]. The incidence of periodontal treatments is closely and consistently related to socio-demographic factors, including age, sex, race, household income, insurance, and health status, and living area $[7,8]$. The severity of disease, and the incidence of periodontal treatments, is higher among those in disadvantaged groups, including, individuals who are older, poorer, less educated, and those living in rural areas $[9,10]$. In addition, although there is no clear evidence, both public health policy and insurance availability are considered to have an impact on PD treatment efficacy and outcome [11-14].

Universal health care was implemented in Korean in 1989. By 2013, $97.1 \%$ of the Korean population (51.34 million people) was covered by the mandatory social National Health Insurance Service (NHIS) [15]. Insurance for 49.99 million people is provided by NHIS, and the Medical Aid Program (MAP) insures an additional 1.46 million people. The dental health-care service was implemented after the medical-care service and it continues to expand. Major dental insurance policies presently cover the costs of sealant (first and second molars, from May 2013), full complete dentures (from July 2012), removable partial dentures (from July 2013), and dental implant treatment (from July 2014) for individuals aged 75 years and above. They also cover the cost of periodontal scaling (for individuals 20 years and above, from July 2013) [15]. Dental insurance coverage continues to expand and coverage for full and partial dentures, and dental implants is expected to be available by 2015 for individuals aged 70 years and above.

Several studies, such as the National Health and Nutrition Examination Survey (NHANES) from the United States, and the Adult Dental Health Survey from the United Kingdom, have investigated the epidemiology of PD $[11,16]$. These reports are useful for assessing the prevalence of $\mathrm{PD}$, and planning national dental services. However, these studies are based on cross-sectional surveys. This method not only limits the ability to assess changes in the incidence of periodontal treatments over time, but also cannot be used to identify the impact of dental insurance coverage on periodontal treatments. When compared with cross-sectional surveys, a longitudinal study can be used to assess changes in the incidence of periodontal treatments over time and to identify the impact of dental insurance coverage on periodontal treatments [17]. In South Korea, several cross-sectional studies, have investigated the association between PD, national dental policies, and sociodemographic factors. However, an observational cohort study has not been conducted [3, 18]. The Korean National Health Insurance Cohort Database (KNHICD) includes 12 years of accumulated individual sociodemographic factors, and is useful for evaluating changes in the incidence of periodontal treatments. Therefore, the aim of our study was to identify national dental policies, and socio-demographic factors, influencing the incidence of periodontal treatments. To accomplish this aim, we used the comprehensive data, accumulated from 2002 to 2013, in the KNHICD.

\section{Methods}

\section{Study design and data source}

Mandatory national health insurance in South Korea results in a database (DB) of more than one trillion individual cases, involving the entire Korean population of 50 million individuals, and includes data from the start-up of mandatory enforcement of insurance payment benefit in 1977. This DB includes information on qualifications, insurance, medical and dental records, checkups, rare incurable diseases, cancer, and long-term-care insurance services.

The NHIS made the KNHICD available for research purposes in 2013. This nationwide, population-based retrospective cohort study evaluated the association between treatments for PD, national dental policies, and socio-demographic factors of the South Korean population. A random stratified sample of one million Koreans was selected from the DB by the NHIS Big Data Steering Department, using 1,476-stage sampling (of sex, age, and household income level), for the 12 years from 2002 to 2013.

Effective from 2003, records that no longer existed, because of death or emigration, were replaced with records from newborns born in the same year. To protect privacy, the identification number of each patient was anonymized. All personal information is managed solely by NHIS and the request for raw data is offered only with given random identification codes. 
Ethics, consent, and permissions

The project was approved by the NHIS Ilsan Hospital, Goyang, Korea. An ethical approval was also obtained by the NHIS Ilsan Hospital (approval \#2016-03-019).

\section{Study population clinical characteristics}

The KCD-6 (Korean Classification of Disease; modified version of ICD-10 [International Classification of Disease]) guidelines were used to diagnose PD (acute periodontitis [K052]; chronic periodontitis [K053]; periodontosis [K054)]; other PD [K055], and unspecified PD [K056]) according to criteria proposed by the American Academy of Periodontology [19].

The study population was defined as patients who were diagnosed with $\mathrm{PD}$, and treated with periodontal surgery, by a general dentist or a specialized dentist (e.g., periodontist), in 2003. Treatment was defined according to the following NHIS prescription codes: U1051/1052, periodontal flap operation (simple/complicated); U1071/ 1072, bone graft for alveolar bone defects (allogenic, xenogenic, or substitute bone graft/autogenous bone graft); or U1081-1083, guided tissue regeneration (without bone graft/allogenic, xenogenic, or substitute bone graft/autogenous bone graft).

\section{Definition of socio-demographic factors}

Socio-demographic factors were identified from the KNHICD and categorized into the following five groups: sex, age, monthly income, health status, and living area. The groups were further divided (using random stratified analysis by the NHIS Big Data Steering Department) into smaller sub-groups. The factor sex had two groups (male and female participants). Age was divided into eight groups; those $<69$ years were divided into 10-year interval groups and those $>70$ years formed one group. Monthly household income was divided into 41 groups based on the monthly household income of the participants. It was classified into quintiles, with medical aid beneficiaries in the first-quintile group. Based on health status of the participants, three groups were formed as healthy, minor disability, and major disability (using the Handicapped Welfare Law). Finally, the factor living was divided into two groups on the basis of its population; < 50,000 residents was classified as rural and $\geq 50,000$ residents classified as urban.

\section{Statistical analysis}

Chi-square analysis, and univariate and multivariate logistic regression were used to evaluate the association between socio-demographic factors and the prevalence of PD. Odds ratios (ORs) and $95 \%$ confidence intervals (CIs) were calculated in all assessments, and a $P$ value of $<0.05$ was considered indicative of statistical significance. Statistical analyses were performed using
Statistical Analysis System (version 9.2, SAS Institute, Cary, NC, USA) by the Department of Health Insurance Research, Ilsan Hospital, NHIS.

\section{Results}

\section{Characteristics of the study population}

The baseline characteristics of the cohort are presented in Table 1. Of the 1,025,340 individuals included in the study, male $(513,258)$ and female $(512,082)$ patients were equally represented. Patients aged 20-49 years $(526,891)$ accounted for $51.4 \%$ of the population. Additionally, $97.0 \%(994,627)$ of patients were in the NHIS (employees and self-employed); $97.3 \%(998,030)$ were classified as

Table 1 Baseline characteristics of the study cohort

\begin{tabular}{|c|c|c|c|c|c|}
\hline \multirow[b]{3}{*}{ Total } & \multicolumn{2}{|l|}{ Males } & \multicolumn{2}{|l|}{ Females } & \multirow[t]{2}{*}{ Total } \\
\hline & $\bar{n}$ & $\%$ & $\bar{n}$ & $\%$ & \\
\hline & 513258 & $50.1 \%$ & 512082 & $49.9 \%$ & 1025340 \\
\hline \multicolumn{6}{|l|}{ Age group (years) } \\
\hline$\leq 9$ & 71921 & $14.0 \%$ & 64661 & $12.6 \%$ & 136582 \\
\hline $10-19$ & 74447 & $14.5 \%$ & 67495 & $13.2 \%$ & 141942 \\
\hline $20-29$ & 86355 & $16.8 \%$ & 84492 & $16.5 \%$ & 170847 \\
\hline $30-39$ & 95929 & $18.7 \%$ & 91788 & $17.9 \%$ & 187717 \\
\hline $40-49$ & 85646 & $16.7 \%$ & 82681 & $16.1 \%$ & 168327 \\
\hline $50-59$ & 48254 & $9.4 \%$ & 48862 & $9.5 \%$ & 97116 \\
\hline $60-69$ & 34353 & $6.7 \%$ & 41169 & $8.0 \%$ & 75522 \\
\hline$\geq 70$ & 16353 & $3.2 \%$ & 30934 & $6.0 \%$ & 47287 \\
\hline \multicolumn{6}{|l|}{ Household income ${ }^{a}$} \\
\hline First quintile & 70088 & $13.7 \%$ & 84513 & $16.5 \%$ & 154601 \\
\hline Second quintile & 79071 & $15.4 \%$ & 78685 & $15.4 \%$ & 157756 \\
\hline Third quintile & 103744 & $20.2 \%$ & 97450 & $19.0 \%$ & 201194 \\
\hline Fourth quintile & 123727 & $24.1 \%$ & 118422 & $23.1 \%$ & 242149 \\
\hline Fifth quintile & 136628 & $26.6 \%$ & 133012 & $26.0 \%$ & 269640 \\
\hline \multicolumn{6}{|l|}{ Insurance status } \\
\hline MAP & 13049 & $3.2 \%$ & 17664 & $3.4 \%$ & 30713 \\
\hline NHIS, employees & 248048 & $48.3 \%$ & 248549 & $48.5 \%$ & 496597 \\
\hline NHIS, self-employed & 252161 & $49.1 \%$ & 245869 & $48.0 \%$ & 498030 \\
\hline \multicolumn{6}{|l|}{ Health status ${ }^{b}$} \\
\hline Healthy & 494934 & $96.4 \%$ & 503096 & $98.2 \%$ & 998030 \\
\hline Major disability & 5828 & $1.1 \%$ & 3633 & $0.7 \%$ & 9461 \\
\hline Minor disability & 12496 & $2.4 \%$ & 5353 & $1.0 \%$ & 17849 \\
\hline \multicolumn{6}{|l|}{ Living areac } \\
\hline Urban & 460837 & $89.8 \%$ & 459751 & $89.8 \%$ & 920588 \\
\hline Rural & 52421 & $10.2 \%$ & 52331 & $10.2 \%$ & 104752 \\
\hline
\end{tabular}

NHIS National health insurance service, MAP Medical aid program

${ }^{\text {a }}$ Total of 41 groups classified into quintiles (with MAP beneficiaries in the first quintile)

${ }^{\mathrm{b}}$ Classification based on the Handicapped Welfare Law in South Korea ${ }^{c}$ Classification based on rural $(<50,000$ residents) or urban $(\geq 50,000$ residents) living 
having good health status; and $89.8 \%(920,588)$ lived in urban areas.

\section{Incidence of periodontal treatments}

Of the patients diagnosed with PD, $30.8 \%(158,303)$ were male and $31.8 \%(162,800)$ female. The incidence of periodontal treatments increased significantly from 2002 $(n=71,917 ; 7.0 \%)$ to $2013(n=183,312 ; 18.1 \%)$. In 2013, the incidence was higher in female patients $(n=91,856$; $18.1 \%)$, when compared to male patients $(n=91,456$; $18.0 \%$ ). The incidence of periodontal treatments increased in all groups in 2013, except in patients 60-69 years of age. The 1-year incidence rate of PD among those aged 10-19 years increased from $2011(n=5,529 ; 4.1 \%)$ to 2013 ( $n=22,566 ; 18.2 \%$; Fig. 1a). From 2002 to 2013, the accumulated incidence of periodontal treatments peaked among patients $40-49$ years of age, for both male $(n=40,426 ; 47.2 \%)$ and female $(n=39.205 ; 47.4 \%)$ patients. Among those 30-39 years of age and over 70 years of age, the accumulated incidence was higher in male patients than female patients. The accumulated incidence was higher in female patients for all other age groups (Fig. 1b).

The incidence of periodontal treatments increased from 2002 to 2013; this increase was unrelated to household income level. The increase was greatest in the first quintile, from $5.9 \%(n=9,056)$ in 2002 , to $17.9 \%(n=$ 30,388) in 2013 (Fig. 2a). The accumulated incidence of periodontal treatments in the first quintile, which includes the MAP group ( $n=42,102 ; 27.2 \%)$, increased, and was similar to that in the fifth quintile $(n=96,393 ; 35.7 \%)$. The accumulated incidence of periodontal treatments was higher in female patients ( $n=24,277 ; 28.7 \%)$, than male patients $(n=17,825 ; 25.4 \%)$ in the first quintile, similar for both sexes in the fourth quintile $(38,661 ; 31.2 \%$ and $37,042 ; 31.3 \%)$, and higher in male patients $(n=49,286$; $36.1 \%)$, when compared to female patients $(n=47,107$; $35.4 \%$ ), in the fifth quintile (Fig. 2b).

The incidence of periodontal treatments showed a tendency to increase in the NHIS group. In 2002, $7.5 \%$ $(37,368)$ of employees and $6.9 \%(34,412)$ of selfemployed individuals underwent periodontal treatments. In 2013, $18.1 \%(124,315)$ of employees and $18.0 \%$ $(53,782)$ of self-employed individuals underwent treatment. However, from 2008 to 2011, the incidence of periodontal treatments increased sevenfold in the MAP group ( $n=244 ; 1.9 \%$ vs. $n=4,751 ; 13.9 \%)$. In 2013 the period incidence in the MAP group was $17.3 \%(n=$ 5,212 ), which was similar to that in the NHIS group (Fig. 3a). The accumulated incidence in the MAP group was $15.5 \%$, which was significantly lower than that in the NHIS group (32.8\% of employees and $30.8 \%$ of selfemployed). There was no difference between male and female patients in any of the groups (Fig. 3b).

The overall incidence of periodontal treatments increased from 2002 to 2013 , to $19.7 \%(7,688)$ in the minor disability group (Fig. 4a). The accumulated incidence of periodontal treatments differed with health status, and was $19.7 \%$ in the major disability group, $31.4 \%$ in the healthy group, and $34.2 \%$ in the minor disability group. There were no significant differences between men and women in any of these groups (Fig. 4b).

The incidence of periodontal treatments increased from 2002 to 2013, for patients in both urban and rural areas. In 2013, the incidence was $18.0 \%(170,124)$ for urban patients, and $17.2 \%(13,188)$ for rural patients (Fig. 5a). The accumulated incidence of periodontal
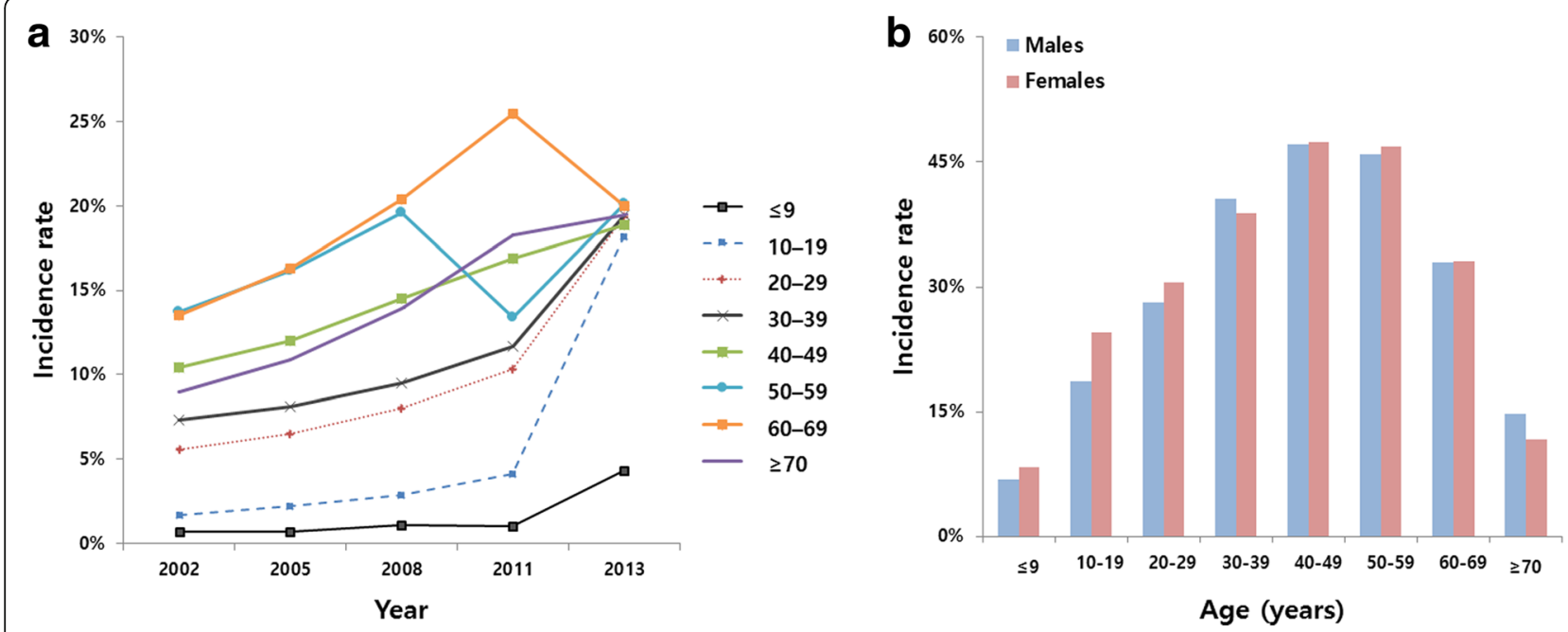

Fig. 1 Age-specific 1-year incidence rates of periodontal treatment (a); and sex-specific accumulated incidence rates of periodontal treatments (b) during 2002-2013 in South Korea 

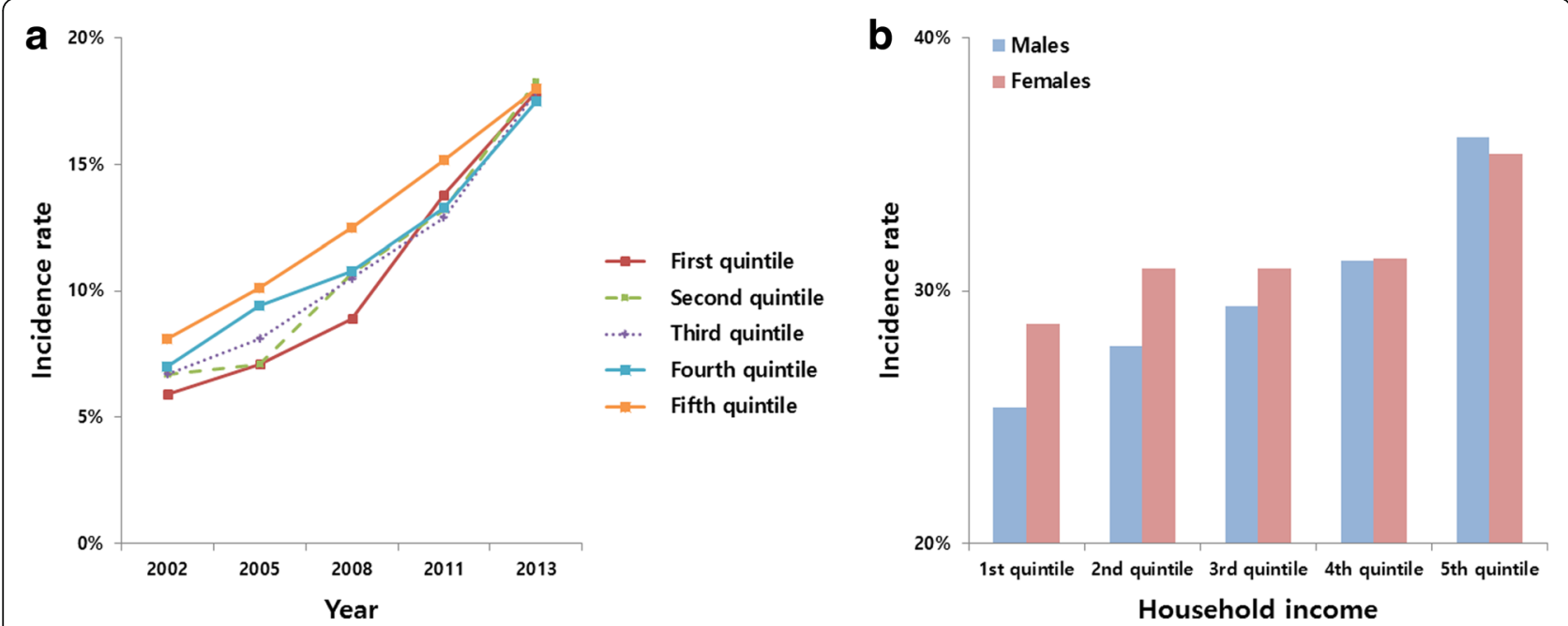

Fig. 2 Household income-specific 1-year incidence rates of periodontal treatment (a); and sex-specific accumulated incidence rates of periodontal treatment (b) during 2002-2013 in South Korea

treatments was $31.9 \%$ in urban areas and $19.7 \%$ in rural areas. There was no significant difference between the sexes (Fig. 5b).

\section{Association of socio-demographic factors with periodon- tal treatments}

The socio-demographic factors associated with periodontal treatments are shown in Table 2. Univariate analysis indicated that all socio-demographic factors investigated were significantly associated with periodontal treatments $(P<0.001)$; however, with multi-variant analysis, the only factor that was not statistically significant was sex $(P=0.513)$. Among all age groups, when using those $\leq 9$ years of age as the reference, the OR for the incidence of periodontal treatments was highest among patients $40-49$ years of age $(\mathrm{OR}=9.58,95 \% \mathrm{CI}=9.36-$ 9.81, $P<0.001)$. For household income, using the first quintile as the reference, the OR was $1.37(95 \% \mathrm{CI}=1.35-1.39$, $P<0.001)$ for the fifth quintile. The incidence of periodontal treatments increased with household income. For insurance status, using the MAP group as the reference, the OR was $1.93(95 \% \mathrm{CI}=1.86-2.00, P<0.001)$ for those in the NHIS (employees) group. For health status, using those in the healthy group as the reference, the major disability group had an OR of 0.61 (95 \% CI $=0.58-0.64, P<0.001)$ and the minor disability group had an OR of 0.94 (95 \% CI $=0.91-0.97, \quad P<0.001)$. When using the urban-area group as the reference for living area, the
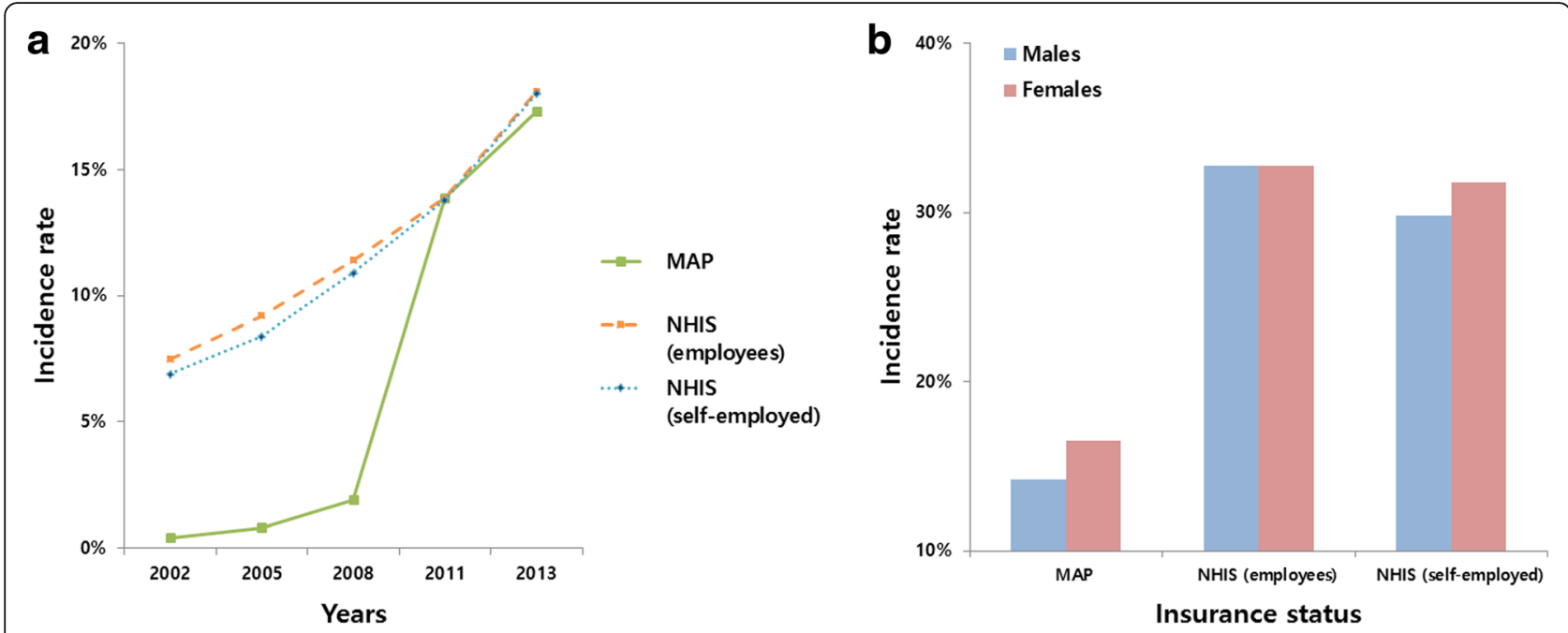

Fig. 3 Insurance status-specific 1-year incidence rates of periodontal treatment (a); and sex-specific accumulated incidence rates of periodontal treatment (b) during 2002-2013 in South Korea. NHIS, National Health Insurance Service; MAP, Medical Aid Program 

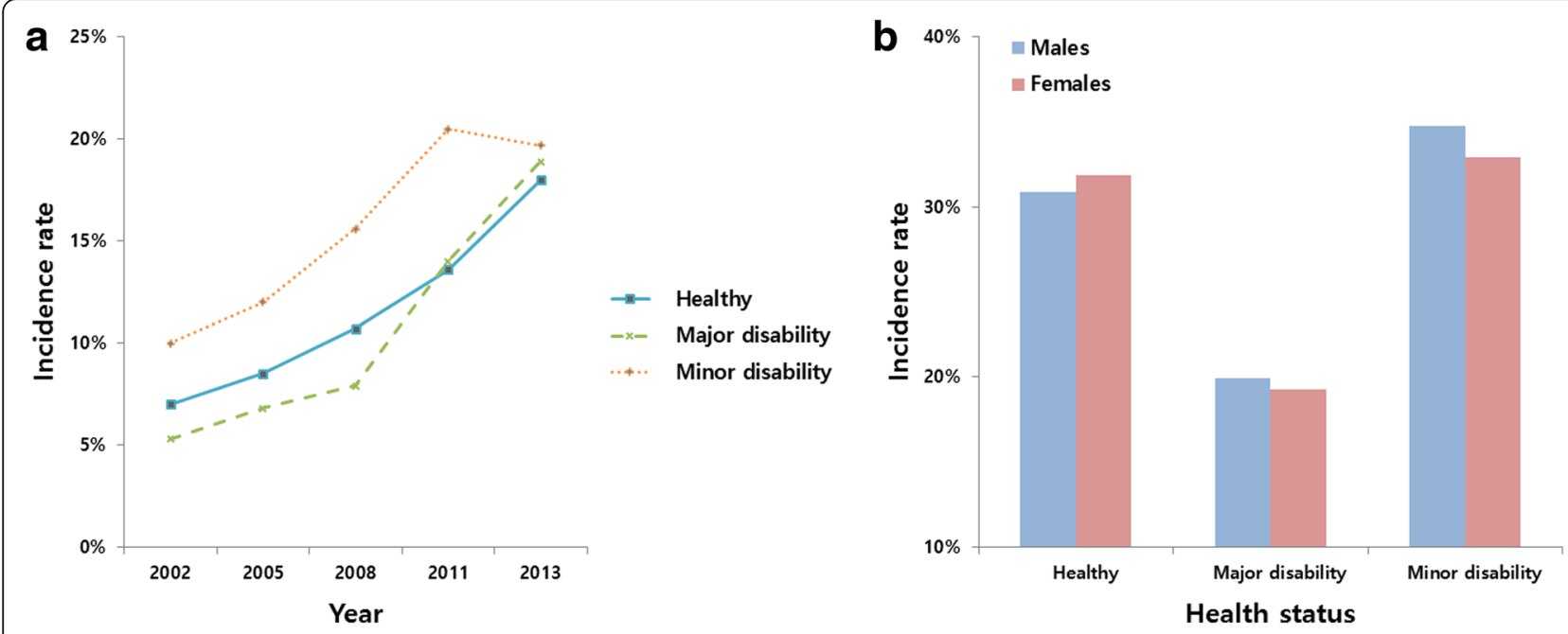

Fig. 4 Health status-specific 1-year incidence rates of periodontal treatment (a); and sex-specific accumulated incidence rates of periodontal treatment (b) during 2002-2013 in South Korea

rural-area group had an OR of $0.85(95 \% \mathrm{CI}=0.83-0.86$, $P<0.001)$.

\section{Discussion}

Based on data in the KNHICD, our study shows that the incidence of periodontal treatments increased significantly from 2002 to 2013 . The increase was seen in both male and female patients, and was due to both sociodemographic factors and the changes in national dental policies. Although there have been reports of sex differences in the incidence of periodontal treatments, this study found similar prevalence rates for both sexes, and that the prevalence for both sexes increased steadily. The incidence of periodontal treatments, according to age, have been influenced by changes in the national dental policies [16, 18]. From 2002 to 2011, the prevalence among individuals less than 20 years of age was similar to previously reported rates $(5-8 \%)[20,21]$. However, in 2013, the incidence of periodontal treatments among those 10 to 19 years of age increased by $18.2 \%$. This increase is likely attributable to expansion of insurance coverage for sealant treatment for those younger than 18 years of age, and to the improved accessibility to dental services, which resulted in an increase in the number of adolescents being diagnosed with periodontal disease.

The difference between the high-incidence age group and the low-incidence age group, excluding those less
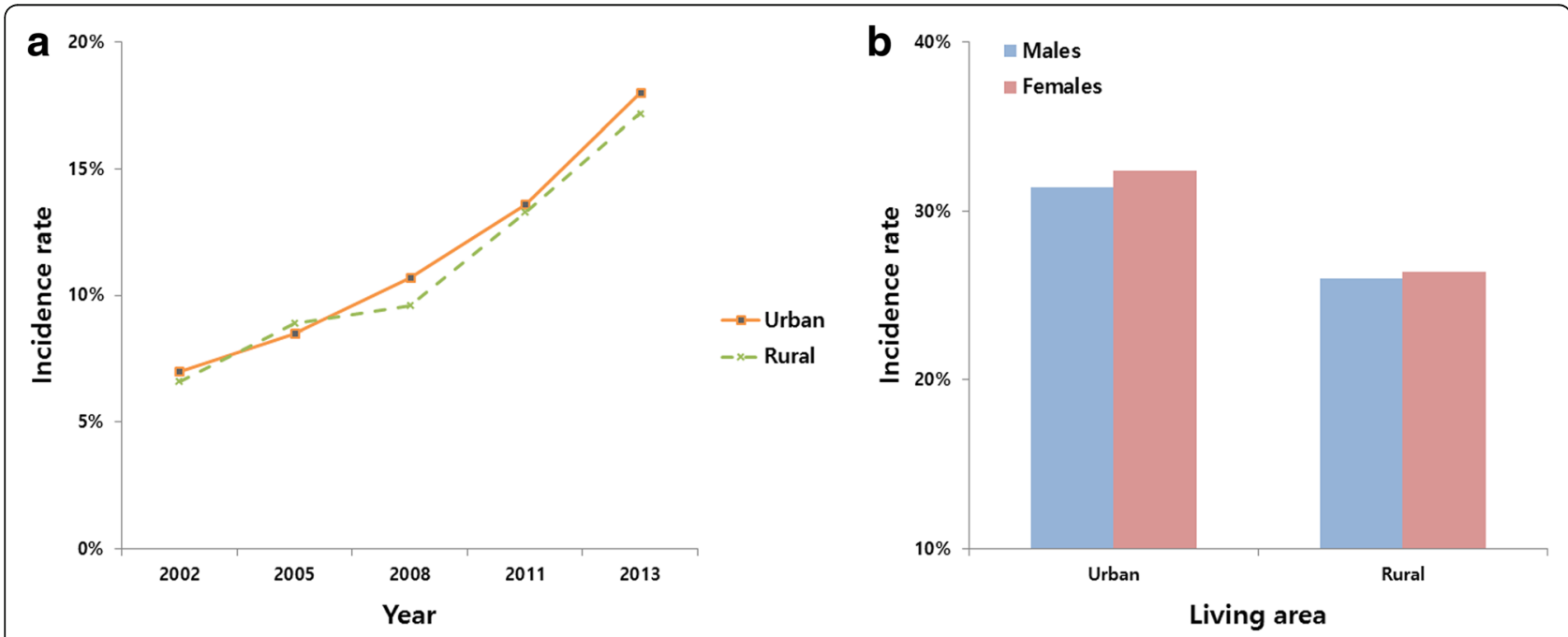

Fig. 5 Living area-specific 1-year prevalence rates of incidence rates of periodontal treatment (a); and sex-specific accumulated incidence rates of periodontal treatment (b) during 2002-2013 in South Korea 
Table 2 Association of sociodemographic factors with periodontal treatments in univariate and multivariate analyses

\begin{tabular}{|c|c|c|c|c|c|c|c|c|}
\hline & \multicolumn{4}{|c|}{ Univariate analysis } & \multicolumn{4}{|c|}{ Multivariate analysis } \\
\hline & $\overline{\mathrm{OR}}$ & & $95 \% \mathrm{Cl}$ & $P$ & $\overline{O R^{a}}$ & & $95 \% \mathrm{Cl}$ & $P$ \\
\hline \multicolumn{9}{|l|}{ Sex } \\
\hline Male & 1.00 & ref & & & 1.00 & ref & & \\
\hline Female & 1.05 & & $1.04-1.05$ & $<0.001$ & 1.00 & & $1.00-1.01$ & 0.513 \\
\hline \multicolumn{9}{|l|}{ Age group (years) } \\
\hline$\leq 9$ & 1.00 & ref & & & 1.00 & ref & & \\
\hline $10-19$ & 3.35 & & $3.27-3.43$ & $<0.001$ & 3.50 & & $3.41-3.58$ & $<0.001$ \\
\hline $20-29$ & 5.10 & & $4.98-5.21$ & $<0.001$ & 5.19 & & $5.07-5.32$ & $<0.001$ \\
\hline $30-39$ & 8.10 & & $7.92-8.28$ & $<0.001$ & 7.72 & & $7.55-7.90$ & $<0.001$ \\
\hline $40-49$ & 11.02 & & $10.77-11.26$ & $<0.001$ & 9.58 & & $9.36-9.81$ & $<0.001$ \\
\hline $50-59$ & 10.61 & & $10.36-10.86$ & $<0.001$ & 8.39 & & $8.18-8.60$ & $<0.001$ \\
\hline $60-69$ & 6.05 & & $5.90-6.20$ & $<0.001$ & 4.67 & & $4.54-4.80$ & $<0.001$ \\
\hline$\geq 70$ & 1.17 & & $1.72-1.84$ & $<0.001$ & 1.64 & & $1.58-1.70$ & $<0.001$ \\
\hline \multicolumn{9}{|l|}{ Household income } \\
\hline First quintile & 1.00 & ref & & & 1.00 & ref & & \\
\hline Second quintile & 1.11 & & $1.09-1.13$ & $<0.001$ & 1.02 & & $1.00-1.04$ & 0.029 \\
\hline Third quintile & 1.15 & & $1.14-1.17$ & $<0.001$ & 1.10 & & $1.08-1.12$ & $<0.001$ \\
\hline Fourth quintile & 1.22 & & $1.20-1.23$ & $<0.001$ & 1.18 & & $1.16-1.20$ & $<0.001$ \\
\hline Fifth quintile & 1.49 & & $1.47-1.51$ & $<0.001$ & 1.37 & & $1.35-1.39$ & $<0.001$ \\
\hline \multicolumn{9}{|l|}{ Insurance status } \\
\hline MAP & 1.00 & ref & & & 1.00 & ref & & \\
\hline NHIS, employees & 2.66 & & $2.58-2.74$ & $<0.001$ & 1.93 & & $1.86-2.00$ & $<0.001$ \\
\hline NHIS, self-employed & 2.42 & & $2.34-2.50$ & $<0.001$ & 1.65 & & $1.59-1.71$ & $<0.001$ \\
\hline \multicolumn{9}{|l|}{ Health status } \\
\hline Healthy & 1.00 & ref & & & 1.00 & ref & & \\
\hline Major disability & 0.54 & & $0.51-0.56$ & $<0.001$ & 0.61 & & $0.58-0.64$ & $<0.001$ \\
\hline Minor disability & 1.14 & & $1.10-1.17$ & $<0.001$ & 0.94 & & $0.91-0.97$ & $<0.001$ \\
\hline \multicolumn{9}{|l|}{ Living area } \\
\hline Urban & 1.00 & ref & & & 1.00 & ref & & \\
\hline Rural & 0.77 & & $0.76-0.78$ & $<0.001$ & 0.85 & & $0.83-0.86$ & $<0.001$ \\
\hline
\end{tabular}

OR Odds ratio, NHIS National health insurance service, MAP Medical aid program ${ }^{\mathrm{a} O R}$, calculated by multivariate

than 9 years of age, can be explained by limited accessibility to dental services $[7,22]$. In 2013, with the expansion of dental insurance coverage to include dentures and implants the incidence of periodontal treatments was expected to increase for individuals over 70 years of age. The incidence of periodontal treatments was lower in individuals with severe disabilities, and those living in rural areas. Although previous studies report the incidence of periodontitis was higher in the elderly and lowincome individuals, the present study did not confirm these results. Decreased accessibility to dental services, due to individual socio-demographic characteristics, and lifestyle risk factors, may explain the different results [22]. Factors such as SES, health behaviors, and general health problems are associated with tooth loss. The main socio-demographic factors associated with tooth loss are, older age, low income, and low education level. Other oral-health-related factors, such as smoking, inadequate brushing habits, noncompliance with dental treatment, and poor dental knowledge, are also associated with tooth loss. General health factors related to tooth loss include coronary heart disease, diabetes, high blood sugar level, and limited physical activity [7, 8].

South Korea is an ethnically and culturally a homogeneous nation. In 2014, the population included only $3 \%$ foreigners, mostly Mongoloid Chinese [23]. Therefore, unlike multiethnic countries, there are few racial barriers present in South Korea; hence, economic barriers are 
considered to be the most important factors restricting access to dental health-care services [24]. To overcome the SES disparities, various public health and insurance policies have been implemented. However, our study found that the disadvantaged groups still experience difficulties in accessing dental treatment. The incidence of periodontal treatments was $25.4 \%$ among male patients in the first quintile of household income, and $36.1 \%$ among those in the fifth quartile; the corresponding rates for female patients were $28.7 \%$ and $35.4 \%$. This difference is attributed to an excessive number of voluntary non-reimbursable dental treatments, even when patients are covered by health insurance.

Prior to 2008, the incidence of periodontal treatments was significantly lower in the MAP group when compared to the NHIS group (comprising employees and self-employed). The incidence of periodontal treatments has increased in the MAP group since 2008, and it was similar (14.1\%) to that in the NHIS group. This increase is likely associated with 2008 changes in public health and insurance policies, which included the secondary poor population into the NHIS group. Policy changes were aimed at moderating the rapid increases in public expenditure on the MAP; however, these changes had no effect on the incidence of periodontal treatment in the MAP group.

Periodontal disease is characterized by chronic, irreversible, and progressive periodontal tissue destruction. Early detection of PD tends to be difficult, due to the absence of symptoms and lack of pain in early disease [25]. In addition, although still controversial, several studies have found a relationship between PD and comorbidities, such as cardiovascular disease, diabetes, premature birth, erectile dysfunction, and Alzheimer's disease $[26,27]$. The incidence of periodontal treatments in the present study increased from 2002 to 2013. This increase is likely due to improvements in accessibility to dental health-care service, rather than an increase in the number of periodontally compromised patients.

The paradigm for dental insurance policies has changed in recent years, to focus on prevention and early diagnosis. Specifically, since 2013, there has been an expansion of dental insurance coverage to include periodontal scaling, dentures, and dental implants and it is expected that the incidence of periodontal treatments will continue to increase. Our study did not evaluate dental records or include detailed diagnostic codes, which limited the ability to diagnose the severity of PD. In addition, although there are still many uninsured voluntary non-reimbursable treatments for dental care, these data are not included in the KNHICD. These issues represent a limitation of the analysis performed in the present study. Nevertheless, in order to evaluate changes in the incidence of periodontal treatments, we used a precisely extracted cohort from the KNHICD, which includes data from all citizens of South Korea, as well as information from medical institutions. The results of this study suggest that national dental policies and socio-demographic factors are closely related to changes in the incidence of periodontal treatments, suggesting that this study will be useful in establishing dental policies that decrease the incidence of $\mathrm{PD}$, and enhance the oral health of the entire population of South Korea.

\section{Conclusions}

Based on data in the KNHICD from 2002 to 2013, this study shows that the incidence of periodontal treatments has increased steadily, in both male and female patients, in South Korea. This study shows that the national dental policies and socio-demographic factors are clearly related to the incidence of periodontal treatments. Specifically, expansion of insurance coverage for dental treatments appears to be related to the increased incidence of periodontal treatment.

\section{Abbreviations \\ DB: Database; ICD: International classification of disease; KCD: Korean classification of disease; KNHICD: Korean national health insurance cohort database; MAP: Medical aid program; NHANES: National health and nutrition examination survey; NHIS: National health insurance service; \\ OECD: Organization for economic cooperation and development; PD: Periodontal disease; SES: Socioeconomic status}

\section{Acknowledgements}

This study used a national sample cohort data of the National Health Insurance Service (NHIS-2016-3-005)

\section{Funding}

This research was supported by Wonkwang University in 2016.

Availability of data and materials

Data will not be made available as additional articles are expected to be published.

\section{Authors' contributions \\ $J H L$ prepared the initial drafts of the manuscript. All authors contributed to the study design and oversight. JHL, JSL, JKC, HIK, YTK, and SHC conducted the data collection. JHL and JKC conducted the analyses. YTK and SHC are supervisor of the study and assisted in drafting of the manuscript. All authors contributed to the manuscript refinement and are responsible for its content. All authors read and approved the final manuscript.}

\section{Authors' information \\ $J H L$, Department of Periodontology, Daejeon Dental Hospital, Wonkwang University College of Dentistry, JSL and SHC, Department of Periodontology, Research Institute for Periodontal Regeneration, Yonsei University College of Dentistry, JKC, Department of Health Insurance Research, Ilsan Hospital, National Health Insurance Service, HIK and YTK, Department of \\ Periodontology, Ilsan Hospital, National Health Insurance Service.}

\section{Competing interests}

The authors declare that they have no competing interests.

Consent for publication

Not applicable. 


\section{Ethics approval and consent to participate}

All cohort data was anonymous and the project was approved by the NHIS Ilsan Hospital, Goyang, Korea. An ethical approval was also obtained by the NHIS IIsan Hospital (approval \#2016-03-019).

\section{Author details}

'Department of Periodontology, Daejeon Dental Hospital, Wonkwang University College of Dentistry, Daejeon 35233, South Korea. ${ }^{2}$ Department of Periodontology, Research Institute for Periodontal Regeneration, Yonsei University College of Dentistry, 50 Yonsei-ro, Seodaemun-gu, Seoul 03722, South Korea. ${ }^{3}$ Department of Health Insurance Research, Ilsan Hospital, National Health Insurance Service, Goyang 10444, South Korea. ${ }^{4}$ Department of Periodontology, Ilsan Hospital, National Health Insurance Service, 100 Ilsan-ro Ilsan-donggu, Goyang 10444, South Korea.

Received: 21 June 2016 Accepted: 25 October 2016

Published online: 05 November 2016

\section{References}

1. Petersen PE. The World Oral Health Report 2003: Continuous improvement of oral. Community Dent Oral Epidemiol. 2003;31(1):3-23.

2. Vettore MV, Faerstein E, Baker SR. Social position, social ties and adult's ora health: 13 year cohort study. J Dent. 2016;44:50-6.

3. Kim DW, Park JC, Rim T, Jung UW, Kim CS, Donos N, et al. Socioeconomic disparities of periodontitis in Koreans based on the KNHANES IV. Oral Dis. 2014:20:551-9.

4. Akhter R, Hassan NMM, Aida J, Zaman KU, Morita M. Risk indicators for tooth loss due to caries and periodontal disease in recipients of free dental treatment in an adult population in Bangladesh. Oral Health Prev Dent. 2008;6:199-207.

5. Tonetti MS, Chapple ILC, Jepsen S, Sanz M. Primary and secondary prevention of periodontal and peri-implant diseases Introduction to, and objectives of the 11th European Workshop on Periodontology consensus conference. J Clin Periodontol. 2015;42 Suppl 16:1-4.

6. Outpatient disease statistics [Internet]. Health Insurance Review \& Assessment Service. Available at http://opendata.hira.or.kr/op/opc/ olapHifraSicklnfo.do. Accessed 17 Oct 2016.

7. Celeste RK. Contextual effect of socioeconomic status influences chronic periodontitis. J Evid Based Dent Pract. 2007;7:29-30.

8. Celeste RK, Nadanovsky P, De Leon AP, Fritzell J. The individual and contextual pathways between oral health and income inequality in Brazilian adolescents and adults. Soc Sci Med. 2009;69:1468-75.

9. Gil-Montoya JA, De Mello ALF, Barrios R, Gonzalez-Moles MA, Bravo M. Ora health in the elderly patient and its impact on general well-being: a nonsystematic review. Clin Interv Aging. 2015;10:461-7.

10. Moore PA, Weyant RJ, Mongelluzzo MB, Myers DE, Rossie K, Guggenheimer J, et al. Type 1 diabetes mellitus and oral health: assessment of periodontal disease. J Periodontol. 1999:70:409-17.

11. Steele J, Shen J, Tsakos G, Fuller E, Morris S, Watt R, et al. The interplay between socioeconomic inequalities and clinical oral health. J Dent Res. 2015;94:19-26.

12. Tseveenjav B, Suominen AL, Vehkalahti MM. Oral health-related behaviours among dentate adults in Finland: findings from the Finnish Health 2000 Survey. Eur J Oral Sci. 2012;120:54-60.

13. Morales A, Carvajal P, Romanelli H, Gomez M, Loha C, Esper ME, et al. Prevalence and predictors for clinical attachment loss in adolescents in Latin America: Cross-sectional study. J Clin Periodontol. 2015;42:900-7.

14. Kossioni AE. Current status and trends in oral health in community dwelling older adults: a global perspective. Oral Health Prev Dent. 2013;11:331-40.

15. Korean statistical information service [Internet]. Statistics Korea. accessed on 17 October 2016; Available at Outpatient disease statistics [Internet]. Health Insurance Review \& Assessment Service. Available at http://kosis.kr/ statisticsList/statisticsList_01List.jsp?vwcd=MT_ZTITLE\&parmTabld=M_01_01. Accessed 17 Oct 2016

16. Eke PI, Dye BA, Wei L, Slade GD, Thornton-Evans GO, Borgnakke WS, et al. Update on prevalence of periodontitis in adults in the United States: NHANES 2009 to 2012. J Periodontol. 2015:86:611-22.

17. Laaksonen M, Prattala R, Lahelma E. Sociodemographic determinants of multiple unhealthy behaviours. Scand J Public Health. 2003:31:37-43.
18. Lee MY, Chang SJ, Kim CB, Chung WG, Choi EM, Kim NH. Community periodontal treatment needs in South Korea. Int J Dent Hyg. 2015;13:254-60

19. Armitage GC. Development of a classification system for periodontal diseases and conditions. Ann Periodontol. 1999;4:1-6.

20. Jenkins WM, Papapanou PN. Epidemiology of periodontal disease in children and adolescents. Periodontol. 2001;26:16-32.

21. Albandar JM, Tinoco EM. Global epidemiology of periodontal diseases in children and young persons. Periodontol. 2002;29:153-76.

22. Jung SH, Ryu Jl, Jung DB. Association of total tooth loss with sociobehavioural health indicators in Korean elderly. J Oral Rehabil. 2011;38:517-24

23. Kim SH, Han MS, Kim W, Kim W. Y chromosome homogeneity in the Korean population. Int J Legal Med. 2010;124:653-7.

24. Long SK, Karpman M, Kenney GM, Wissoker D, Anderson N, Zuckerman S. Taking Stock: Health Insurance Coverage under the ACA as of December 2014. Urban Institute. 2015.

25. Pihlstrom BL, Michalowicz BS, Johnson NW. Periodontal diseases. Lancet. 2005:366:1809-20.

26. Kebschull M, Demmer RT, Papapanou PN. "Gum bug, leave my heart alone!"-epidemiologic and mechanistic evidence linking periodontal infections and atherosclerosis. J Dent Res. 2010:89:879-902.

27. Lee JH, Lee JS, Park JY, Choi JK, Kim DW, Kim YT, et al. Association of lifestyle-related comorbidities with periodontitis: a nationwide cohort study in Korea. Medicine (Baltimore). 2015;94:e1567.

\section{Submit your next manuscript to BioMed Central and we will help you at every step:}

- We accept pre-submission inquiries

- Our selector tool helps you to find the most relevant journal

- We provide round the clock customer support

- Convenient online submission

- Thorough peer review

- Inclusion in PubMed and all major indexing services

- Maximum visibility for your research

Submit your manuscript at www.biomedcentral.com/submit
) Biomed Central 